\title{
Pengaruh Meditasi Diiringi Musik Religi Terhadap Kualitas Tidur Pada Penderita Hipertensi di RW 2 Desa Gadung Driyorejo Gersik
}

\author{
Lono Wijayanti \\ Universitas Nahdlatul Ulama Surabaya, lono@unusa.ac.id \\ Puji Astuti \\ Universitas Nahdlatul Ulama Surabaya, puji@unusa.ac.id \\ Rahayu Anggraini \\ Universitas Nahdlatul Ulama Surabaya, angrek@unusa.ac.id
}

\begin{abstract}
Abstrak
Kebutuhan tidur yang tidak cukup, seringnya terbangun di tengah malam maupun lamanya waktu yang dibutuhkan sejak terjaga hingga terlelap sering memicu untuk terjadinya peningkatan tekanan darah pada penderita hipertensi. Tujuan penelitian adalah menganalisis pengaruh meditasi diiringi musik religi terhadap kualitas tidur pada penderita hipertensi di RW 2 desa gadung driyorejo gresik. Penelitian ini merupakan penelitian Quasy Experiment pre-post control group design. Populasi dalam penelitian ini adalah seluruh penderita hipertensi sejumlah 60 dan sampel yang digunakan 52 responden menggunakan tehnik simple random sampling. Variabel bebas adalah meditasi diiringi musik religi sedangkan variabel tergantung adalah kualitas tidur. Data dalam penelitian ini dianalisis menggunakan uji statistik Wilcoxon dan Mann Whitney. Hasil penelitian menunjukkan bahwa pada kelompok intervensi diperoleh kualitas tidur pretest dan posttest berdasarkan uji Wilcoxon test didapatkan nilai $\mathrm{p}=0,000(\mathrm{p}<0,05)$, dan pada kelompok kontrol nilai $\mathrm{p}=1,000$. Berdasarkan uji Mann-Whitney diperoleh nilai $\mathrm{p}=0,000$, sehingga dapat disimpulkan bahwa terdapat perbedaan perubahan kualitas tidur antara kelompok kontrol dan kelompok intervensi secara signifikan. Meditasi diiringi musik religi berdampak positif terhadap kualitas tidur. Penggunaan meditasi diiringi musik religi dapat dipertimbangkan sebagai salah satu intervensi dalam memperbaiki kualitas tidur yang dapat laksanakan secara rutin bahkan setiap hari khususnya pada penderita hipertensi.
\end{abstract}

Kata kunci: kualitas tidur, meditasi diiringi musik religi, hipertensi

\begin{abstract}
The need for insufficient sleep, often waking up in the middle of the night and the length of time needed from wakefulness to sleep often triggers an increase in blood pressure in people with hypertension. The purpose of this study was to analyze the effect of meditation accompanied by religious music on sleep quality in hypertensive patients in RW 2, Gadung Driyorejo, Gresic Village. This research is a Quasy Experiment pre-post control group design study. The population in this study were all 60 hypertension sufferers and the sample used was 52 respondents using simple random sampling technique. The independent variable is meditation accompanied by religious music while the dependent variable is sleep quality. Data in this study were analyzed using Wilcoxon and Mann Whitney statistical tests. The results showed that in the intervention group the quality of pre and post sleep was obtained based on the Wilcoxon test $p$ value $=0,000(p<0.05)$, and in the control group the value of $p=1,000$. Based on the Mann-Whitney test, the value of $p=0,000$ was obtained, so it can be concluded that there are significant differences in sleep quality changes between the control group and the intervention group. Meditation accompanied by religious music has a positive impact on sleep quality. The use of meditation accompanied by religious music can be considered as one of the interventions in improving sleep quality that can be carried out routinely even every day, especially in patients with hypertension.
\end{abstract}

Keywords: sleep quality, meditation accompanied by religious music, hypertension 


\section{PENDAHULUAN}

Faktor penting bagi kesehatan dan kualitas hidup seseorang salah satunya adalah kualitas tidur. Tidur merupakan kebutuhan manusia sehari-hari untuk berbagai alasan seperti untuk mengatasi stres, mencegah kelelahan, mengumpulkan energi, memulihkan pikiran dan tubuh, serta untuk dapat menikmati hidup secara penuh (Kozier et.al., 2011).

Fenomena di masyarakat saat ini, banyak penderita mengeluh sulit tidur, tidur sering terbangun pada malam hari, sehingga berdampak pada tekanan darah, mengeluh pusing dan lemas saat bangun tidur di pagi harinya. Berdasarkan penelitian Lumantow, dkk (2016), menunjukkan kualitas tidur memiliki hubungan dengan tekanan darah dengan nilai $p$-value sebesar 0,000 dimana kualitas tidur yang buruk berpengaruh terhadap terjadinya prehipertensi pada remaja.

Berdasarkan penelitian yang dilakukan Shittu et.al. (2014), bahwa status kesehatan jangka panjang dapat dipengaruhi oleh kualitas tidur, dimana dari hasil penelitiannya didapatkan bahwa kualitas tidur yang buruk dapat mempengaruhi terjadinya peningkatan tekanan darah ( $p$ value 0,002), peningkatan body mass index (p-value 0,045$)$, dan terjadinya depresi ( $p$ - value 0,000). Peningkatan tekanan darah yang disebabkan oleh kondisi kurang tidur dapat mempengaruhi keseimbangan hormon kortisol (hormon penanda stres). Ketidakseimbangan hormon kortisol dapat menyebabkan ketidakseimbangan hormon yang dihasilkan oleh kelenjar adrenal salah satunya adalah katekolamin yang terdiri dari epinefrin dan noreprinefrin yang bekerja pada saraf simpatis yang menyebabkan vasokontriksi vaskuler (Potter \& Perry, 2010; Smeltzer \& Bare, 2013).

Hipertensi merupakan gangguan pada pembuluh darah yang mengakibatkan suplai oksigen dan nutrisi yang dibawa oleh darah terhambat ke jaringan tubuh (Wahyuningsih, 2013). Hipertensi atau yang lebih dikenal dengan sebutan tekanan darah tinggi adalah suatu keadaan dimana seseorang mengalami peningkatan tekanan darah diatas normal. Hipertensi merupakan faktor resiko utama dari penyakit jantung dan stroke. Penyakit hipertensi juga disebut sebagai "the silent killer" karena banyak orang yang tidak dapat melihat tanda-tanda atau gejala dari luar. Perkembangan hipertensi berjalan secara perlahan, tetapi secara potensial sangat berbahaya (Syamsiah, 2017).

Fenomena di masyarakat saat ini, banyak penderita mengeluh mengenai kondisi tekanan darah yang tinggi. Mereka 
mengkonsumsi obat penurun tekanan darah, tanpa mengetahui efek samping yang merugikan bagi tubuh. Penderita yang mengalami kenaikan tekanan darah merasakan pusing, sulit tidur, dan sering terbangun malam hari bila tekanan darah tidak kunjung turun.

\section{Data World Health Organization} (WHO) tahun 2012 menunjukkan, di seluruh dunia sekitar 972 juta orang atau 26,4\% penghuni bumi mengidap hipertensi dengan perbandingan $26,6 \%$ pria dan $26,1 \%$ wanita. Angka ini kemungkinan akan meningkat menjadi 29,2\% di tahun 2030. Penduduk Indonesia yang mengalami hipertensi sebesar 23,3\% (WHO, 2014).

Berdasarkan data dari Riskesdes (2018), kejadian hipertensi di Indonesia adalah sebesar $34,1 \%$. Survey Indikator Kesehatan Nasional (SIRKENAS) tahun 2016 pravelensi hipertensi meningkat menjadi $32,4 \%$. Surveilan terpadu penyakit puskesmas di Jawa Timur menunjukkan jumlah kunjungan penderita hipertensi meningkat dari tahun 2014 dengan total 530.070 pengunjung menjadi 536.199 pengunjung di tahun 2015.

Berdasarkan profil Dinas Kesehatan Kota Surabaya kejadian hipertensi di Surabaya dari tahun ke tahun selalu berada dalam 10 daftar penyakit terbanyak. Pada tahun 2011 kejadian hipertesi 3,30\%. Pada tahun 2012 sedikit menurun menjadi 3,06\%. Pada tahun 2013 meningkat pesat menjadi 13,6\%. Pada tahun 2014 menurun menjadi $3 \%$ dan menempati urutan ke tujuh (Dinkes Jatim, 2015).

Pengobatan non farmakologis dapat menurunkan tekanan darah salah satunya meditasi (Martin \& Mardian, 2016). Dengan meditasi seseorang akan merasa rileks, damai, tenteram, mampu menambah keimanan dan mengantisipasi terjangkit berbagai penyakit. Karena, di dalam tubuh manusia terdapat jaringan psiko-neuroendokrin yang berpengaruh terhadap faktor kejiwaan seseorang. Jaringan tersebut berpengaruh terhadap sistem kekebalan tubuh (Zainul, 2007).

Terapi meditasi dapat mempengaruhi aktifitas syaraf otonom, yaitu saraf yang mengatur tekanan darah, serta menenangkan aktifitas di dalam sistem syaraf simpatik, sehingga terjadi pelebaran pembuluh darah, kemudian adanya pernafasan yang dalam akan meningkatkan sirkulasi oksigen, sehingga otot-otot cenderung mengendur dan memperlancar aliran darah serta berpengaruh untuk menurunkan tingkat stress dan menurunkan tekanan darah pada penderita hipertensi (Magfiroh, 2013). Sedangkan terapi musik akan memberikan 
suasana rileks dan damai sehingga membuat denyut jantung dan tahanan pembuluh darah menjadi normal. Musik menimbulkan reaksi psikologis yang membuat pendengarnya rileks sehingga dapat menghilangkan stress, mengatasi kecemasan dan menumbuhkan kesadaran spiritual (Aizid, 2011). Dengan kondisi tubuh riles tersebut diharapkan kualitas tidur seseorang menjadi lebih baik.

\section{METODE}

Penelitian ini merupakan penelitian kuantitatif menggunakan desain quasy experimental, dengan metode pre post test with control group design. Penelitian ini dilaksanakan di RW 2 desa gadung driyorejo gresik. Populasi dalam penelitian ini adalah seluruh penderita hipertensi berjumlah 60, jumlah sampel 52 responden yang dibagi menjadi dua kelompok yaitu kelompok kontrol 26 orang dan intervensi 26 orang dengan teknik sampling menggunakan simple random sampling.

Pada kelompok intervensi diberi perlakuan meditasi diiringi musik religi dilakukan secara berkelompok dengan durasi 20 menit, dilakukan satu hari dua kali selama 1 minggu, sedangkan pada kelompok kontrol hanya perawatan biasa tanpa intervensi apapun. Instrumen penelitian menggunakan Pittsburgh Sleep Quality
Index (PSQI) dalam bentuk kuesioner untuk mengukur kualitas tidur. Data dianalisa dengan menggunakan uji Wilcoxon dan Mann Whitney.

\section{HASIL PENELITIAN \\ Data Umum}

\section{Jenis Kelamin}

Tabel 1. Distribusi Frekuensi Responden berdasarkan Jenis Kelamin.

\begin{tabular}{lllll}
\hline \multirow{2}{*}{ Variabel } & \multicolumn{2}{l}{ Intervensi } & \multicolumn{2}{l}{ Kontrol } \\
\cline { 2 - 5 } & $\mathrm{n}$ & $\%$ & $\mathrm{n}$ & $\%$ \\
\hline 1) Laki-laki & 8 & 30,8 & 10 & 38,5 \\
\hline 2) Perempuan & 18 & 69,2 & 16 & 61,5 \\
\hline Total & 26 & 100 & 26 & 100 \\
\hline \multicolumn{2}{l}{ Sumber: Data primer 2019} & &
\end{tabular}

Berdasarkan tabel.1 menunjukkan bahwa sebagian besar responden berjenis kelamin perempuan pada kedua kelompok.

2. Usia

Tabel 2. Distribusi Frekuensi Responden berdasarkan Usia.

\begin{tabular}{llccc}
\hline \multirow{2}{*}{ Variabel } & \multicolumn{2}{l}{ Intervensi } & \multicolumn{2}{l}{ Kontrol } \\
\cline { 2 - 5 } & $\mathrm{n}$ & $\%$ & $\mathrm{n}$ & $\%$ \\
\hline 1) $26-35$ & 4 & 15,4 & 1 & 3,8 \\
\hline 2) $36-45$ & 1 & 3,8 & 6 & 23,1 \\
\hline 3) $46-55$ & 11 & 42,8 & 14 & 53,8 \\
\hline 4) $56-65$ & 8 & 30,8 & 5 & 19,2 \\
\hline 5) 66 keatas & 2 & 7,7 & 0 & 0 \\
\hline Total & 26 & 100 & 26 & 100 \\
\hline
\end{tabular}

Sumber: Data primer 2019

Berdasarkan tabel.2 menunjukkan bahwa persentase terbesar responden berusia 46-55 tahun pada kedua kelompok. 


\section{Data Khusus}

1. Kualitas Tidur

Tabel 3. Perubahan kualitas pre dan post diberikan meditasi diiringi musik religi

\begin{tabular}{lcccccc}
\hline $\begin{array}{l}\text { Meditasi } \\
\text { Diiringi } \\
\text { Musik }\end{array}$ & \multicolumn{3}{c}{ Bualitas Tidur } & \multicolumn{2}{c}{ Total } \\
Religi & $\mathrm{f}$ & $\%$ & $\mathrm{f}$ & $\%$ & $\mathrm{n}$ & $\%$ \\
\hline Sebelum & 1 & 3,8 & 25 & 96,2 & 26 & 100 \\
Sesudah & 26 & 100 & 0 & 0 & 26 & 100 \\
\hline Wilcoxon test & $p$ value $=0,000$ & \multicolumn{3}{c}{$\mathrm{z}=-5,000$} \\
\hline
\end{tabular}

Sumber: Data primer 2019

Berdasarkan tabel 3 menunjukkan bahwa berdasarkan uji Wilcoxon test diperoleh nilai signifikansi $p(0,000)<\alpha$ $(0,05)$ yang artinya ada perbedaan kualitas tidur sebelum dan sesudah dilakukan intervensi meditasi diiringi musik religi pada kelompok intervensi.

Tabel 4. Perubahan kualitas pre dan post pada kelompok kontrol

\begin{tabular}{cccccccc}
\hline $\begin{array}{c}\text { Perawatan } \\
\text { biasa/tanpa }\end{array}$ & \multicolumn{4}{c}{ Kualitas Tidur } & \multicolumn{2}{c}{ Total } \\
intervensi & $\mathrm{F}$ & $\%$ & $\mathrm{~F}$ & $\%$ & $\mathrm{n}$ & $\%$ \\
\hline Sebelum & 6 & 23 & 20 & 77 & 26 & 100 \\
Sesudah & 7 & 27 & 19 & 73 & 26 & 100 \\
\hline Wilcoxon test & \multicolumn{4}{c}{$p$ value $=1,000$} & & $\mathrm{z}=0,000$
\end{tabular}

Sumber: Data primer 2019

Berdasarkan tabel 4 menunjukkan bahwa hasil uji Wilcoxon test diperoleh nilai signifikansi $p(1,000)>\alpha(0,05)$ yang artinya tidak ada perbedaan kualitas tidur sebelum dan sesudah dilakukan perawatan biasa pada kelompok kontrol.
Tabel 5 Hasil Perbedaan Kualitas Tidur Pada Kelompok Intervensi dan Kontrol

\begin{tabular}{cccc}
\hline $\begin{array}{c}\text { Perbedaan Kualitas } \\
\text { Tidur Pre Dan post }\end{array}$ & Jumlah & $\begin{array}{c}p \\
\text { value }\end{array}$ & $\mathrm{Z}$ \\
\hline Intervensi & 26 & & \\
Kontrol & 26 & & $-5,646$ \\
\hline
\end{tabular}

Sumber: Data primer 2019

Berdasarkan tabel 5 dapat diketahui bahwa perbedaan kualitas tidur pada kelompok intervensi dan kelompok kontrol pada klien yang menderita hipertensi di RW 2 desa gadung driyorejo gersik setelah dilakukan uji statistik dengan Mann-Whitney diperoleh nilai $p(0,000)<\alpha(0,05)$ yang berarti ada perbedaan kualitas tidur antara kelompok intervensi dan kelompok kontrol.

\section{PEMBAHASAN}

Berdasarkan tabel 1 menunjukkan bahwa sebagiaan besar responden berjenis kelamin perempuan 69,2\% pada kelompok intervensi dan kelompok kontrol 61,5\%. Sedangkan pada tabel 2, Berdasarkan usia mayoritas berusia dengan rentang 46-55\% pada kelompok intervensi 42,8\% dan pada kelompok kontrol 53,8\%.

Secara klinis memang tidak terdapat perbedaan yang signifikan, namun setelah usia 45 tahun wanita akan mengalami menopause sehingga wanita akan beresiko terdapat penyakit hipertensi ringan, sedangkan pada laki-laki usia lebih dari 31 
tahun sudah beresiko terhadap hipertensi ringan. Hal tersebut karena terdapat perbedaan secara fisiologis dalam system kardiovaskular antara laki-laki dan perempuan, termasuk kadar hormon yang terlibat dalam sistem peredaran darah.

Kasus hipertensi cenderung akan meningkat seiring dengan bertambahnya usia seseorang, Menurut Sunaryati (2011) tingkat normal tekanan darah bervariasi sepanjang kehidupan. Tekanan darah pada orang dewasa cenderung meningkat seiiring dengan bertambahnya usia karena akan terjadi kemunduran fungsi dari seluruh tubuh secara progresif. Elastisitas pembuluh darah arteri juga semakin berkurang dan menjadi kaku. Keadaan ini dapat menyebabkan arteri menjadi tidak dapat mengembang saat jantung memompa darah, sehingga darah yang mengalir menjadi tidak lancar. Peningkatan kasus hipertensi akan terus berkembang pada usia 50-60 tahun.

Hasil penelitian awal (pre intervensi) menunjukkan bahwa pada kelompok intervensi menunjukkan hampir seluruhnya dengan kualitas tidur buruk yaitu 96,2\% dan dengan kualitas tidur baik hanya 3,8\%. Sedangkan pada kelompok kontrol sebagian besar (77\%) kualitas tidur responden buruk dan sebagian kecil (23\%) memiliki kualitas tidur baik.
Pada kelompok intervensi, berdasarkan hasil analisis pada tabel 5.2 dengan uji Wilcoxon test diperoleh nilai $p$ value $(0,000)<\alpha(0,05)$. Ini menunjukkan bahwa ada perbedaan kualitas tidur pre dan post setelah diberikan intervensi meditasi diiringi musik religi yang signifikan. Hal ini dibuktikan dengan adanya perubahan kualitas tidur menjadi lebih baik yaitu seluruhnya $100 \%$ responden dengan kualitas tidur baik.

Berdasarkan hasil penelitian pada kelompok kontrol, tidak ada perbedaan kualitas tidur pre dan post. Hal ini ditunjukkan dengan uji Wilcoxon test dan diperoleh nilai $p$ value $=1,000$ yang artinya tidak ada perbedaan kualitas tidur pre dan post. Pada kelompok kontrol, klien hanya melakukan rileksasi nafas biasa. Berdasarkan hasil tersebut peneliti berpendapat bahwa rileksasi nafas biasa yang dilakukan klien kurang efektif dikarenakan klien kurang fokus dan klien melakukan seadanya seperti nafas yang dilakukan setiap hari sehingga kurang adanya penghayatan yang berdampak pada kualitas tidur.

Menurut Shittu et.al. (2014), kualitas tidur yang buruk memiliki dampak negatif yang besar terhadap status kesehatan jangka panjang, dimana dari hasil penelitiannya 
didapatkan bahwa kualitas tidur yang buruk dapat memengaruhi terjadinya peningkatan tekanan darah ( $p$-value 0,002$)$, peningkatan body mass index (p-value 0,045), dan terjadinya depresi (p-value 0,000). Terjadinya peningkatan tekanan darah disebabkan oleh kondisi kurang tidur yang dapat memengaruhi keseimbangan hormon kortisol (hormon penanda stres). Ketidakseimbangan hormon kortisol akan menyebabkan ketidakseimbangan hormon yang dihasilkan oleh kelenjar adrenal salah satunya adalah katekolamin yang terdiri dari epinefrin dan noreprinefrin yang bekerja pada saraf simpatis yang menyebabkan vasokontriksi vaskuler (Potter \& Perry, 2010; Smeltzer \& Bare, 2013).

Meditasi yang diiringi musik religi dalam penelitian ini merupakan suatu kegiatan relaksasi yang bertujuan untuk memperbaiki kondisi psikologis agar menjadi lebih rileks dan mengurangi kesakitan. Dengan melibatkan olah jiwa dan pengosongan pikiran dari hal-hal yang membebani tubuh, serta memfokuskan pikiran pada lantunan syair yang mengandung pesan moral maupun unsur ajaran agama yang terkandung di dalam lantunan lagu. Dalam terapi meditasi diiringi musik religi dapat menghasilkan respon relaksasi di dalam tubuh, seperti menyeimbangkan emosi dan mental, penurunan laju nadi, nafas menjadi teratur, relaksasi otot, serta relaksasi pembuluh darah yang dapat menurunkan tahanan perifer dan dapat menurunkan tekanan darah (Martin \& Mardian, 2016). Berdasarkan teori Pigion (2010) metode relaksasi sangat optimal untuk gangguan pola tidur serta dapat menjadi teknik yang termudah untuk dipelajari pasien.

Terapi meditasi diiringi musik religi Deen Assalam dan Ya Habibal Qalbi dalam penelitian ini dilakukan dengan durasi 20 menit, dua kali perhari selama 1 minggu secara rutin dan berturut-turut. Asumsi peneliti bahwa untuk mencapai kondisi rileks pada seseorang sangat bergantung pada kemampuan individu masing-masing, namun bila dilakukan secara rutin dan konsentrasi maka akan memperoleh kondisi yang betul-betul rileks. Dengan meditasi dapat mengembalikan tubuh pada kondisi yang tenang. Beberapa teknik meditasi selain menyebabkan efek yang menenangkan fisik, juga dapat menangkan pikiran, serta membuat tidur menjadi lebih baik (L Wijayanti dkk,2019).

Hasil penelitian ini ditunjang dengan penelitian yang dilakukan Mas'adah (2018) yaitu tentang pengaruh relaksasi meditasi benson terhadap pemenuhan kebutuhan tidur 
lansia di balai sosial lanjut usia di mandalika mataram, hasil penelitian ini menyebutkan bahwa tehnik relaksasi meditasi benson berpengaruh positif terhadap pemenuhan kebutuhan tidur lansia dengan nilai $\mathrm{p}$ value 0,000 .

\section{SIMPULAN}

Simpulan dari hasil penelitian ini adalah responden yang diberi pendampingan terapi meditasi diiringi musik religi mengalami perubahan kualitas tidur menjadi lebih baik dibandingkan klien yang tidak diberi pendampingan terapi meditasi diiringi musik religi. Dan pada penderita hipertensi di RW 2 Desa Gadung Driyorejo Gersik dapat melaksanakan terapi meditasi diiringi musik religi setiap hari secara mandiri. Berdasarkan data tersebut hasil penelitian ini dapat dijadikan rujukan dalam pembuatan protap di rumah sakit untuk memperbaiki kualitas tidur pada klien hipertensi dengan SOP yang telah dibuat.

\section{DAFTAR PUSTAKA}

Aizid, Rizem. 2011. Sehat Dan Cerdas Dengan Terapi Musik. Yogyakarta: Laksana.

Bistara, D.N. \& Kartini, Y. 2018. Hubungan Kebiasaan Mengkonsumsi Kopi dengan Tekanan Darah Pada Dewasa Muda. Jurnal Kesehatan Vokasi Vol.3 No. 1. Universitas Gajah Mada. http://scholar.google.co.id. Diakses pada tanggal 12 Juni 2019

Depkes. 2013. Riset Kesehatan Dasar. http://www.depkes.go.id/resources/do wnload/general/hasil\%202013.pdf. Diakses pada 21 Desember 2018.

Dinkes Jatim. 2015. Survailens Terpadu Penyakit Puskesmas tahun 2014 \& 2015. Dinas kesehatan Jawa Timur.

L Wijayanti, EM Wardani\&DN Bistara. 2019. Autogenic Relaxation with Aromaterapy Cendana On the Quality of Sleeping In Patients Diabetes Type 2Mellitus.

https://www.thejnp.org/index.php/jnp/ article/view/68. diakses pada tanggal 23 Nopember 2019.

Martin, Weddy \& Ponia Mardian. 2016. Pengaruh Terapi Meditasi Terhadap Perubahan Tekanan Darah Pada Lansia Yang Mengalami Hipertensi Vol. 10 No. 4. STIKES Ceria Bukittinggi.

http://scholar.google.co.id. Diakses pada tanggal 21 September 2018

Mas'adah. 2018. Pengaruh Relaksasi Meditasi Benson Terhadap Pemenuhan Kebutuhan Tidur Lansia Di Balai Sosial Lanjut Usia Mandalika Mataram. Adi Husada Nursing Journal Vol.4 No.1, Juni 2018.

Magfiroh Nasruliyah Hikmatul. 2013. Peranan Terapi Relaksasi Meditasi Dalam Menurunkan Stres Pada Penderita Hipertensi. Universitas Muhammadiyah Malang.

Potter, P. A., \& Perry, A. G. 2010, Fundamental of Nursing, Edisi 7 vol 3, Salemba Medika, Jakarta.

Pigeon WR. 2010. Diagnosis, Prevalence, Pathways, Consequences, and 
Treatment of Insomnia. Indian Journal of Medicine. 2010; 131: 321-332.

Shittu, R., Issa, B. A., Olanrewaju, G. T., Odeigah, L. O., Sule, A. G., Sanni., M. A., et al. 2014, Association between Subjective Sleep Quality, Hypertension, Depression and Body Mass Index in a Nigerian Family Practice Setting, J Sleep Disorder Ther, 3 (2), 157.

Sunaryati, S.S. 2011. 14 Penyakit Paling Sering Menyerang dan Mematikan. Jogjakarta: Flash Books.

World Health Organanizations (WHO). 2015.

http://www.who.int/diseases/publicati ons/global_brief_hypertensions/en/ diakses pada tanggal 21 September 2018.

Zainul, Zen. 2007. Kekuatan Metode Lafidzi Hidup Sehat Dengan Lahir, Fikir Dan Dzikir. Jakarta: Qultum Media. 